\title{
PRESYNAPTIC INHIBITION IN THE LATERAL GENICULATE BODY INDUCED BY STIMU- LATION OF THE CEREBRAL CORTEX
}

\author{
Kitsuya Iwama, Hisatoshi Sakakura and Takuji Kasamatsu \\ Laboratory of Neurophysiology, Institute of Higher Nervous Activity, \\ Osaka University Medical School, Kita-ku, Osaka
}

Following the first description on the presynaptic inhibition by Frank and Fourtes (1957), Eccles and his associates have found that this type of synaptic inhibition is widely distributed in the mammalian central nervous system (ECcles, Eccles and MAGNi, 1961 ; Schmidt and Willis, 1963b ; Eccles, Schmidt and Willis, 1963d; Andersen, Brooks and Eccles, 1963 ; Andersen, Eccles, Schmidt and Yokota, 1964).

In this paper it will be shown that repetitive stimulation of some areas of the cerebral cortex exerts upon the terminals of the optic tract (OT) an effect which is readily explained in terms of the presynaptic inhibition. Some of its important properties will be described.

\section{METHODS}

Cats, weighing $2.5-4.5 \mathrm{~kg}$, were used. Under ether anesthesia a canula was connected with the trachea and a polyethylene tubing was inserted into the saphenous vein. Then, administration of ether was discontinued and immobilization with Flaxedil was started maintaining the animal on artificial respiration. Necessary operations and experiments were conducted under this condition.

For stimulating the OT and for recording its action potential, bipolar electrodes were used which were made of two insulated steel wires cemented side by side with exposed tips about $0.5-1.5 \mathrm{~mm}$ apart. First, a pair of electrodes were inserted into the optic chiasma searching for discharges in response to photic stimulation with a single flash. Then, another pair of electrodes were introduced into the lateral geniculate body (LGB), using a response to single shock stimulation of the optic chiasma as a guide. After a LGB response was encountered with the standard potential pattern. (BisHoP and MACLEOD, 1954; VAstola, 1957), the electrodes were fixed in place. Usually both eyes were enucleated after completing the placement of these two pairs of electrodes. Stimulation of the cortical surface was made with a pair of ball-tipped silver wire electrodes which were placed gently on the exposed cortical surface. The tip distance of the cortical electrodes were usually less than $5 \mathrm{~mm}$.

Received for publication January 31, 1965

岩間吉世, 阪食久稔, 笠松卓爾 
An electrical stimulus applied to the OT was a rectangular, $0.05 \mathrm{msec}$ pulse with variable intensities. For cortical surface stimulation we used a variable number of $0.5 \mathrm{msec}$ pulses at $100-300 / \mathrm{sec}$. All the stimulus pulses were delivered by NihonKohden electronic stimulators. For amplification and registration of the electrical activities of the OT, R-C-coupled amplifiers of a short time constant (Nihon-Kohden, type AVM-2) were used in conjunction with a dual beam cathode ray oscillograph (Nihonkohden, type VC-7).

Most experiments described in this paper were designed to examine changes in excitability of the OT terminals following cortical conditioning stimulation. For this purpose, the antidromic action potential of the OT, elicited by single shock stimulation with the geniculate electrodes and recorded from the optic chiasma, was used as an index. Usually five records were taken each for the control response and the conditioned one. Excitability change of the OT terminals was evaluated with the average amplitude of the conditioned response in per cent of the control (WALL, 1958; ECCLES, Eccles and MAGni, 1961 ; Eccles, Schmidt and Willis, 1963a; Schmidt and Willis, 1963b). In experiments examining cortically induced effects upon the orthodromic action potential of the OT, the recordings were made in the same way as above but using the chiasmatic electrodes for stimulation and the geniculate ones for recording. In both types of experiment the time interval between the cortical conditioning stimulus and the peripheral testing one was varied widely. When the cortical stimulation was made with repetitive shocks, the test interval was measured with reference to its first shock.

\section{RESULTS}

1. Antidromic and orthodromic action potential of the OT. A typical example of the antidromic action potential of the OT is illustrated in FIG. 1. It was a positive spike potential composed of three distinct deflections, suggesting that there were activated three groups of fibers differing in conduction velocity. It is likely that the first two deflections represent activity of the $t_{1}$ and $t_{2}$ fibers of P. O. BISHOP, respectively, because the conduction velocities calculated on the basis of the peak times roughly correspond to those reported previously (BISHOP, JEREMY and LANCE, 1953). This view is supported by comparing the antidromic response with the orthodromic one which is obtainable with the same arrangement of the electrodes. The orthodromic response so obtained is reproduced in FIG. 1 with the same time scale as in the antidromic recording. According to the interpretation of the previous authors (BISHOP and MACLEOD, 1954; VASTOLA, 1957), the first positive-negative deflection and the following negative one represent action potentials of the terminals of the $t_{1}$ and $t_{2}$ fibers, respectively, and the last negative component is due to the activity of the postsynaptic neurons. It is seen that the first two positive peaks of the antidromic response well coincide in time with the first two negative peaks of the orthodromic response.

It was most usual that between the first two components of the antidromic response, the $t_{2}$ component was recorded with a larger amplitude than the $t_{1}$ component. But sometimes this relation was reversed according to the site of 


\section{Orthodromic response}

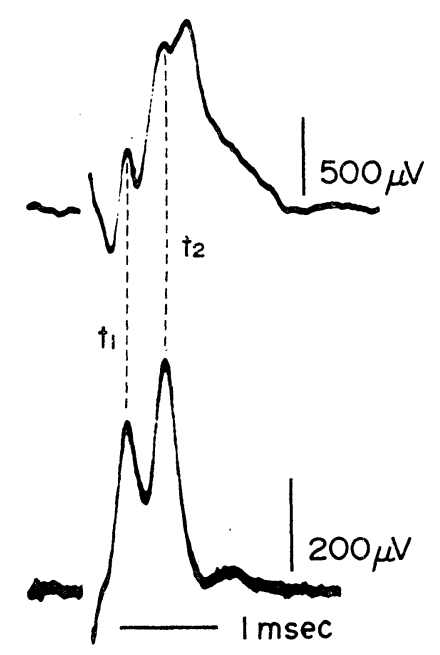

FIG. 1. Antidromic and orthodromic action potentials of the OT. A pair of bipolar electrodes were each in the optic chiasma and the LGB. The antidromic response was obtained using the chiasmatic electrodes for recording and the geniculate ones for stimulation. For the orthodromic recording the same pairs of electrodes were used but with their functions converted. In this and all subsequent figures, negativity was indicated downward for the antidromic response and upward for the orthodromic one.

\section{Antidromic response}

the electrode tip within the optic chiasma and the intensity of stimulation. As to the third component, it was noted that this component was quite variable; sometimes it appeared with a relatively large amplitude (FIGS. 4 and 5), but in other cases it was insignificantly small only marking a notch on the descending limb of the $t_{2}$ deflection (FIG. 2). Moreover, it was often observed that this slowest component of the antidromic response tended to decrease in size and to lengthen its peak time as the animal deteriorated. These facts made it difficult to use this component as an index for evaluating the cortically induced action.

2. Facilitation of the antidromic OT response by cortical conditioning stimulation. FIG. 2 illustrates the results of an experiment in which effects of conditioning stimulation to the visual cortex of both sides were tested with the antidromic OT response produced by stimulation with the electrodes in the LGB of one side. The visual cortical stimulation was made with four pulses at $100 / \mathrm{sec}$.

Sample records and graphs in the upper half of FIG. 2 were obtained with the conditioning and the testing stimulations on the same side. At the test interval of $30 \mathrm{msec}$ there appeared some facilitation of the antidromic response with respect to both $t_{1}$ and $t_{2}$ components. This facilitation increased as the test interval increased and reached its maximum at about $80 \mathrm{msec}$. After this summit the facilitation gradually decreased but it could be traced up to 400 msec. The effects of stimulation of the contralateral visual cortex was found 

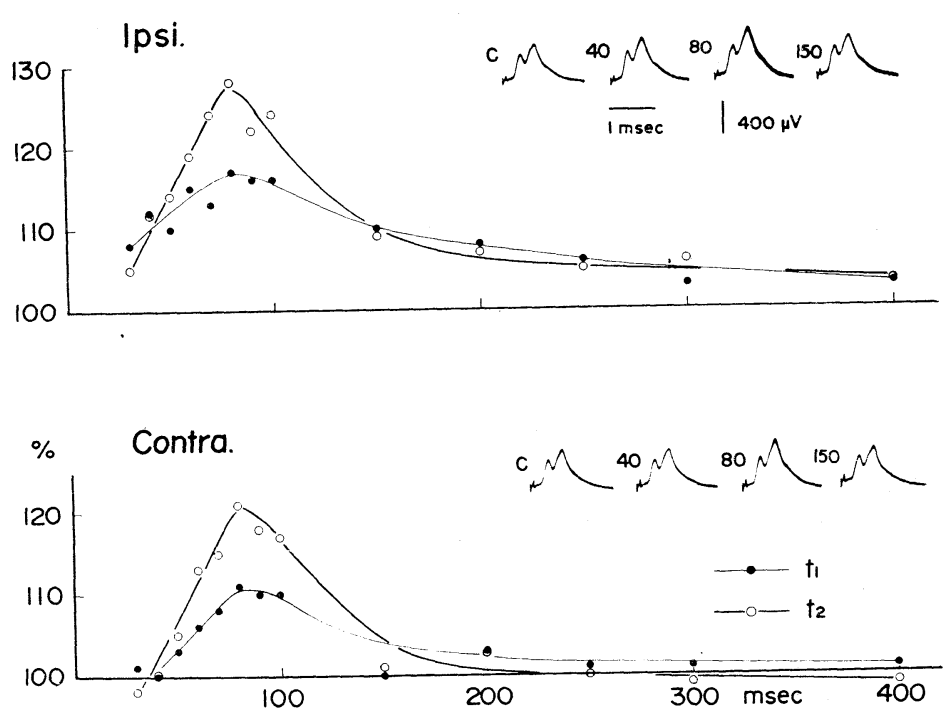

FIG. 2. Time course of facilitation of the antidromic OT response following cortical conditioning stimulation. The conditioning stimulus (4 pulses at $100 /$ sec) was applied to approximately symmetrical points of the visual cortex of both sides. Ordinate: amplitude of conditioned OT response in per cent of the control. Abscissa: time after the first shock of the cortical stimulus. The same convention was used in all subsequent graphs showing the time course of cortical effect. In specimen records, $\mathrm{C}$ means the control and the numbers attached mean the time intervals in msec at which the respective records were obtained after the conditioning stimulus.

about the same as those in the ipsilateral stimulation, except that the effects in the ipsilateral side were generally stronger than in the contralateral side. Through several experiments we have established that if the cortical conditioning stimulation is effective, the facilitation of the antidromic OT response appears with a latency not less than $10 \mathrm{msec}$, reaches the summit at $60-90 \mathrm{msec}$ and continues sometimes beyond $400 \mathrm{msec}$. This is true not only for the visual cortex but also for the remaining effective areas which will be described later.

The facilitatory effect of cortical origin upon the antidromic OT response increases with increasing the intensity or the number of shocks for the cortical stimulation. The effects of increasing the number of cortical shocks is shown in FIG. 3. In this experiment the conditioning stimulation was given to the visual cortex ipsilateral to the OT terminals examined and the number of cortical shocks increased from one to six keeping the stimulus intensity at a given level and the inter-pulse interval at $10 \mathrm{msec}$. It is seen that the maximal facilitation increased from 110 to $130 \%$ as the conditioning shock increased from one to six. In association with this the summit of the facilitation curve 


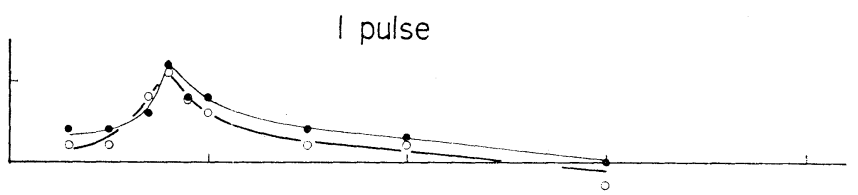

2 pulses
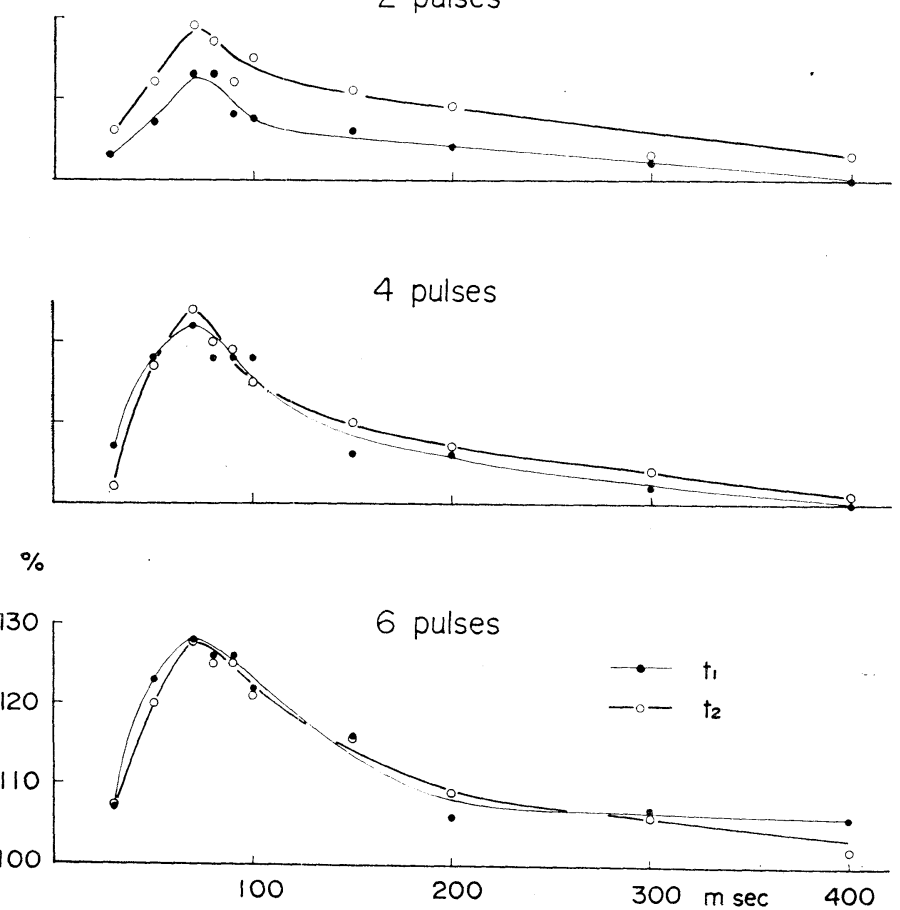

FIG. 3. Time course of facilitation of the antidromic OT response with a varying number of conditioning pulses. The conditioning and testing stimulations were made on the same side. For repetitive pulses of conditioning stimulation the inter-pulse interval was fixed at $10 \mathrm{msec}$.

was gradually shifted from 80 to $70 \mathrm{msec}$.

As to the relative efficacy of cortical conditioning stimulation in facilitation of the $t_{1}$ and $t_{2}$ fibers, it is seen in FIG. 2 that within some range of the test interval around the maximal facilitation the $t_{2}$ fibers received a stronger effect than the $t_{1}$ fibers. This is the most usual finding in our experiment and is independent of the size of the testing antidromic response, as will be seen in FIG. 4. This figure shows the curves of calibrating the amplitude of the antidromic response as a function of the intensity of the testing shock both for the control response and for the conditioned one. The conditioning stimulation was applied to the visual cortex with four pulses at $100 / \mathrm{sec}$ and its effect was examined at the test interval of $90 \mathrm{msec}$. The antidromic stimu- 


\section{Antidromic response}

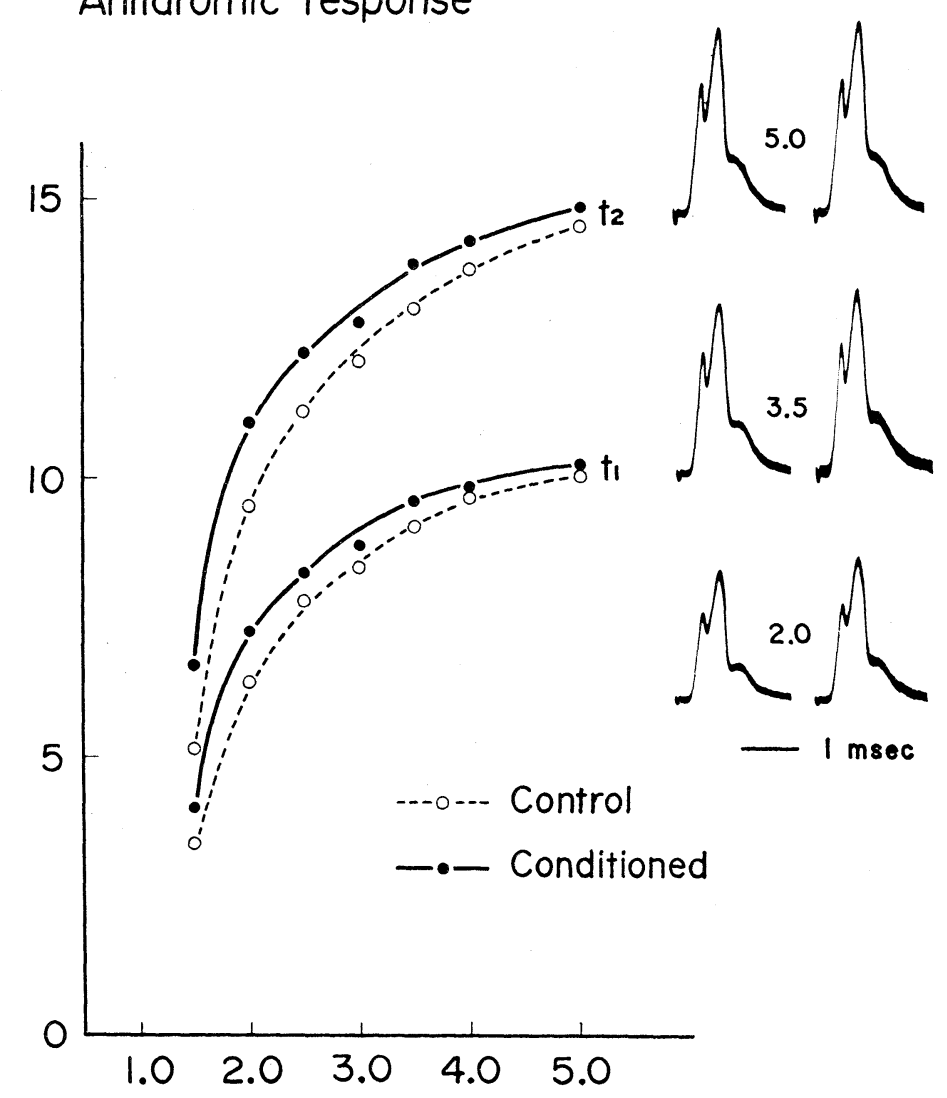

FIG. 4. Calibration curves of amplitude of the antidromic OT response as a function of the intensity of testing stimulation. Both amplitude (ordinate) and stimulus intensity (abscissa) were given in arbitrary units. The conditioned antidromic OT responses were obtained at the conditioningtesting interval of $90 \mathrm{msec}$. Four pulses at $100 / \mathrm{sec}$ were applied as a conditioning stimulus to the ipsilateral visual cortex. Specimen records show the control and conditioned OT responses at three levels of the stimulus intensity as indicated by attached numbers.

lation was applied ipsilaterally to the visual cortex stimulated. The cortical effect can be seen in that the calibration curves of the $t_{1}$ and $t_{2}$ responses were displaced upward relative to the control curves in a wide range of the stimulus intensity. ECCLEs and his associates have shown that the exact measure of the conditioning effect is given by the ratio between the stimulus intensities giving rise the same amplitude of the response with and without the conditioning stimulation (ECCles, ECCles and MAGNi, 1961; Eccles, SchmidT and Willis, 1963a). Following this we obtained $105-115 \%$ for the $t_{1}$ fibers and 
$114-124 \%$ for the $t_{2}$ fibers in the intermediate range of the amplitude.

3. Suppression of the orthodromic OT response by cortical conditioning stimulation. The cortical effect exerted upon the OT terminals could be demonstrated in another way, that is, by using the orthodromically produced action potential of the OT terminals as an index. This is shown in FIG. 5. In this


FIG. 5. Facilitation of the antidromic OT response and suppression of the orthodromic OT response. The ipsilateral visual cortex received conditioning stimulation of four pulses at $100 / \mathrm{sec}$. Letters and numbers attached to the specimen records are used with the same convention as in Fig. 2.

experiment it was first ascertained that cortical conditioning stimulation caused facilitation of the antidromic OT response as usual. This is illustrated in the upper half of FIG. 5 with the curves and the specimen records which were obtained by applying the conditioning and testing stimulations in the same way as in FIG. 2. After obtaining these results, the effect of the same cortical stimulation was examined with the OT terminal response which was elicited by stimulation of the optic chiasma and recorded from within the LGB, keeping the assembly of electrodes in the same positions as before. It was found 
that when the spike potentials of the OT terminals were subjected to the cortically induced action, they were suppressed more or less. This suppression lasted for a long time after the cortical stimulation with approximately the same time course as in facilitation of the antidromic response. It was noted, however, that the summit of the suppression curve is slightly shifted toward left relative to that of the facilitation curve. Concerning the differential effect upon the $t_{1}$ and $t_{2}$ fibers, it was seen that activity of the $t_{2}$ fibers was more strongly suppressed than that of the $t_{1}$ fibers, a phenomenon corresponding to the differential facilitation of the antidromic $t_{1}$ and $t_{2}$ responses.

It is thus established that the cortical conditioning stimulation is effective in modifying the functional state of the OT in two ways, that is, facilitation of the antidromic response to stimulation of the terminals and suppression of the activity of the terminals to orthodromically conducted volleys. Since these two phenomena are closely coupled with each other, they are most likely to signify the presynaptic inhibition. A further discussion on this point will be made in a later section.

4. Cortical areas evoking facilitatory effects upon the antidromic OT response. Attempts were made to find how the points capable of exerting the facilitatory effect upon the antidromic OT response were distributed over the cortical surface. The exploration was made by moving the cortical stimulating electrodes from point to point on both sides of the cortical surface. The electrodes for testing stimulation was kept in the LGB of one side.

As shown in FIG. 2, the both sides of the visual cortex did not differ from each other in the time course of facilitation. Furthermore it was shown in some areas other than the visual cortex that if any facilitatory effects could be initiated therefrom, their time courses were about the same as those obtained from the visual cortex. On the basis of these the effects of conditioning stimulation of any cortical points were determined at the fixed test interval giving rise the maximal facilitation.

The results of several experiments were combined and shown in a cortical map where the effective areas were marked with hatches making the degree of facilitation in each effective area to be proportional to the density of the hatch (FIG. 6). The most effective area was located in a posterior half of the lateral gyrus ipsilateral to the OT terminals examined. Surrounding this maximally effective area, the effective points were distributed widely over the dorsal aspect of the cortical surface of both sides, but they were limited mainly within the part posterior to the ansate sulcus. It was unfailingly found that an area covering the middle supra- and ectosylvian gyri had a considerably strong facilitatory effect on the OT terminals of both sides. In some experiments a small area around the coronal sulcus exhibited some facilitatory effect. 


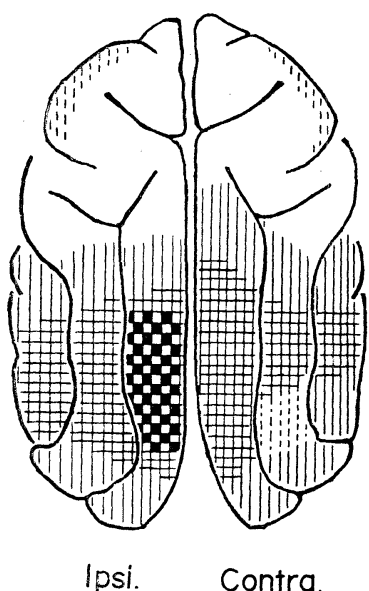

FIG. 6. Cortical areas from which facilitation of the antidromic OT response was elicited. See text.

5. Effects of Nembutal and picrotoxin. The pharmacological properties of the presynaptic inhibition have been extensively studied by Eccles, ScHMidT and WILlis (1963b) and by ScHMIDT (1964) with the primary sensory synapses of the spinal cord. Among many chemicals treated by these workers, we examined in this experiment only the effects of Nembutal and picrotoxin on the cortically induced facilitation of the antidromic OT response.

In FIG. 7 are presented the curves showing the time course of facilitation of the antidromic OT response which was obtained with conditioning stimulation of the visual cortex and testing stimulation of the ipsilateral OT terminals. Before administration of Nembutal unusually high values of the maximal facilitation were obtained at the test interval of $60 \mathrm{msec}$. This is probably because the testing shock used in this experiment was rather weak. Nembutal was injected intravenously in a dose of $5 \mathrm{mg} / \mathrm{kg}$ and this was repeated at intervals of $10-20 \mathrm{~min}$ until the total dose injected amounted to $20 \mathrm{mg} / \mathrm{kg}$. During this time the cortical facilitatory effect gradually decreased, and in the final stage it became very small with the summit time of facilitation slightly reduced. In the average condition of experiment the effect of Nembutal appeared much more drastically. When the cortical facilitatory effect of moderate strength was observed, administration of Nembutal $20-30 \mathrm{mg}$ with a single shot was able to make the cortical conditioning stimulation completely ineffective. Through many experiments we have never observed that the cortical facilitatory effect is enhanced following administration of Nembutal.

As to the effects of picrotoxin, we failed to reach a definitive conclusion. Intravenous injection of this drug in a dose of several hundred $\mu \mathrm{g} / \mathrm{kg}$ made the cortex so highly excitable that high-amplitude, seizure discharges appeared spontaneously or in response to cortical stimulation, and sometimes they continued indefinitely. These seizure discharges seemed to act like the cortical 


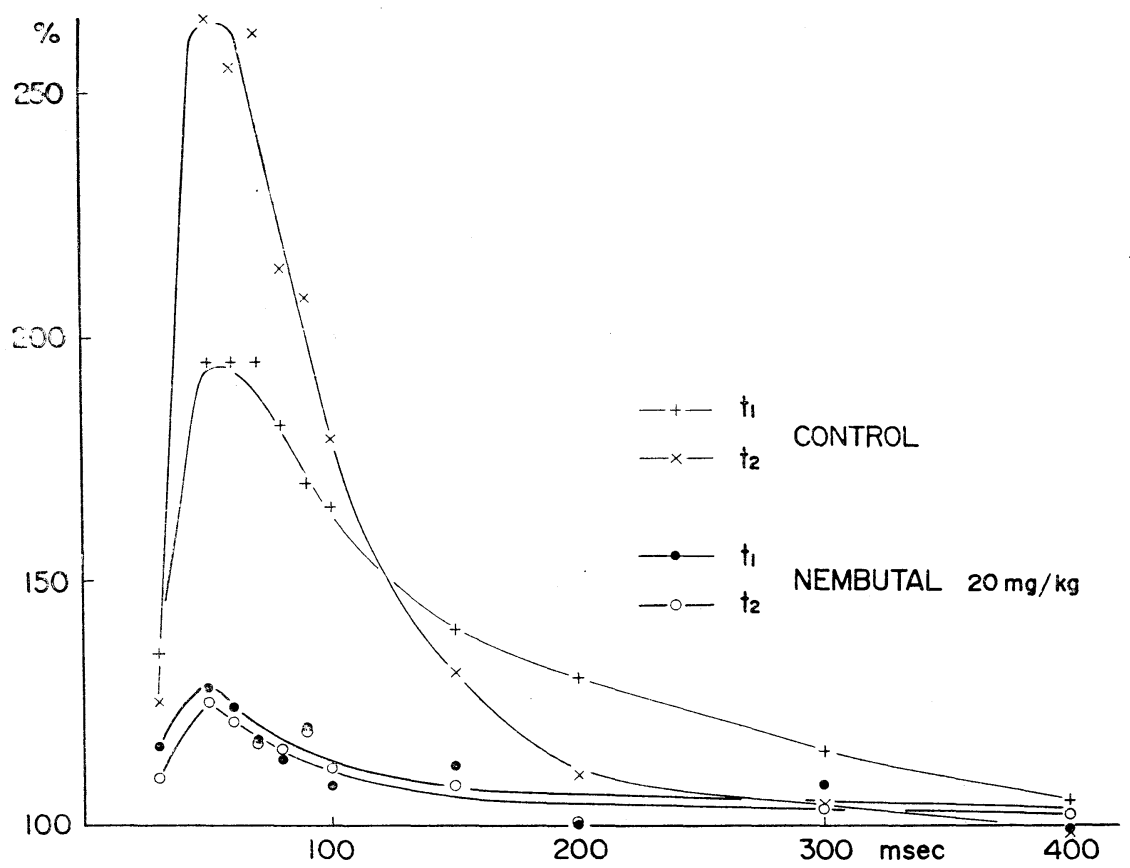

FIG. 7. Effects of intravenous injection of Nembutal upon facilitation of the antidromic OT response. The conditioning stimulation with four pulses at $100 / \mathrm{sec}$ was given to the ipsilateral visual cortex. After the control curves of facilitation were obtained, Nembutal of $5 \mathrm{mg} / \mathrm{kg}$ was injected at intervals of $10-20 \mathrm{~min}$ until the total dose amounted to $20 \mathrm{mg} / \mathrm{kg}$. During this time the facilitatory effects were successively reduced.

conditioning stimulation, so that the testing antidromic OT response became very unstable. Under this condition the effects of the cortical conditioning stimulation were difficult to evaluate.

\section{DISCUSSION}

Recording the antidromically conducted action potential of the OT produced by stimulation of the fiber terminals within the LGB, we have established that it is facilitated for a considerably long time after stimulation of some areas of the cortex. Since this is demonstrable in animals with the eyes enucleated, an acceptable explanation is that the cortical conditioning stimulation is effective to depolarize the OT terminals so that their excitability is increased. This view is supported by the findings of ECCLES and his associates in the presynaptic inhibition in the spinal cord; depolarization of the presynaptic terminals, which was directly observed with the intracellular technique, was found to occur with about the same time course as enhancement of the excitability 
of the terminals which was revealed by antidromic stimulation (ECCLES, MAGNI and Willis, 1962; Eccles, Schmidt and Willis, 1963a, 1963c; ANDERSEN, Eccles, Schmidt and Yokota, 1964 ; Andersen, Eccles and Sears, 1964). If such depolarization of the presynaptic terminals reaches a sufficient intensity, orthodromically conducted volleys of the OT are expected to be reduced or abolished at the presynaptic terminals. As described above, this expectation has been fulfilled in the present experiment in which the anatomical arrangement of the presynaptic terminals in the LBG favors us to access the activity of the terminals with gross electrodes (Bishop and MACLEOD, 1954). Thus, we are led to conclude that the cortically induced effects exerted upon the OT terminals are manifestation of the presynaptic inhibition in the LGB. However, further experiments are required to obtain other lines of more direct evidence.

WIDÉn and AJMONE-MARSAN (1960) studied the behavior of the LGB neurons at the level of unitary activity in interaction of cortical, optic tract and photic stimuli. Later, their findings were confirmed and extended by AJMONEMARSAN and MoRILlo (1961). Among several important findings presented by these workers we are interested in that when a conditioning stimulus was applied to the cortex, there appeared inhibition of the testing response to an optic tract stimulus. This inhibition could be seen with fairly long interstimulus intervals, and also even when a cortical conditioning stimulus produced no sizable responses in the LGB. In view of our finding presented in this paper we suppose that such a corticogeniculate inhibition may be explained, at least partly, in terms of the presynaptic inhibition. As a matter of fact, the distribution of the active spots which WIDÉN and AJMONE-MARSAN (1960) determined on the cortex ipsilateral to the LGB well coincides with that determined by us taking facilitation of the antidromic OT response as an index.

The presynaptic inhibition studied in the present experiment is characterized by a slow time course; it has a long latency, a slow rise time and a long duration sometimes exceeding $400 \mathrm{msec}$. However, such sluggishness of the time course seems not specific to the LGB, because in some sensory synapses where the presynaptic inhibition could be induced by stimulation of both the local afferent fibers and the sensorimotor cortex it was shown that the presynaptic inhibition by the cortical stimulation was effected with a slower time course than by the peripheral stimulation (ANDERSEN, ECCLES, SCHMIdT and Yokota, 1964; Andersen, Eccles and Sears, 1964). It would be reasonable to suppose that there is a complex interneuronal system to mediate the cortically initiated action to the presynaptic terminals of the LGB.

As to the effects of Nembutal upon the presynaptic inhibition Eccles and his associates have revealed that this drug, if not used in a large dose, acts to increase and prolong both the presynaptic inhibition and the associated presynaptic depolarization (Eccles, Schmidt and Willis, 1963c; SchmidT, 1964). This has not been confirmed in the present experiment in which Nembutal has 
been shown to be a depressant in any doses. However, the presynaptic inhibition studied by us seems to involve a more complex neuronal system than that studied by the above-mentioned authors, so that our data are not directly comparable with theirs.

A convulsive dose of picrotoxin has been reported to diminish and to shorten both the presynaptic inhibition and the presynaptic depolarization responsible for the inhibition (Eccles, Schmidt and Willis, 1963c; SchmidT, 1964). Since we have failed to obtain conclusive evidence on this point because of unavoidable side-effects of the drug, a problem has remained unsettled whether or not the presynaptic inhibitory mechanism of the LGB shows the same pharmacological response to picrotoxin as found in the synapses of the spinal cord.

\section{SUMMARY}

Effects of conditioning stimulation of the cerebral cortex upon excitability of the terminals of the optic tract (OT) were examined in unanesthetized cats with immobilization. The cortical stimulation was made with a single shock or repetitive pulses at $100-300 / \mathrm{sec}$.

1. The antidromically conducted action potential of the OT, produced by stimulation of the OT terminals within the lateral geniculate body (LGB) and recorded from the optic chiasma, was enhanced following the cortical conditioning stimulation. This facilitatory effect appeared with a latency not less than $10 \mathrm{msec}$, reached the maximum at about $60-90 \mathrm{msec}$ and continued sometimes beyond $400 \mathrm{msec}$. The facilitation increased with increasing the number of pulses for the cortical conditioning stimulation and was seen with varying the intensity of the testing stimulation in a wide range.

2. The action potential of the terminals of the OT, produced by stimulation of the optic chiasma and recorded from within the LGB, was suppressed by cortical conditioning stimulation. The time course of this suppression was about the same as that of facilitation of the antidromic response of the OT.

3. Combining the above-mentioned findings, it was concluded that the effects of cortical stimulation were manifestation of the presynaptic inhibition in the LGB.

4. In the cortex ipsilateral to the OT terminals examined, a posterior half of the lateral gyrus was the area from which facilitation of the antidromic OT response was most easily elicited. Next to this, stimulation of the middle supra- and ectosylvian gyri was effective. The active spots were found distributed also on the contralateral cortex in about the same way as in the ipsilateral side.

5. Nembutal was effective to suppress the cortical facilitation of the antidromic OT response. Attempts to see the effects of picrotoxin failed to yield conclusive evidence. 
A part of the expenses for the present experiment was defrayed by a grant from the Ministry of Education. We are grateful to Dr. S. KIYONO for his kindly reading the manuscript.

Addendum: According to a personal communication from Drs. Hisao Suzuki and Koiti Motokawa of the Tohoku University Medical School, Sendai, Japan, they have succeeded in demonstrating the presynaptic inhibition of the LGB in cats. The results of their experiment are in good agreement with those presented in this paper.

\section{REFERENCES}

Ajmone-Marsan, C. And Morillo, A. Cortical control and callosial mechanisms in the visual system of cat. Electroenceph. clin. Neurophysiol., 13: 553-563, 1961.

Andersen, P., Brooks, C. McC. And Eccles, J.C. Electrical responses of the ventrobasal nucleus of the thalamus. W. Bargmann and Schadé, J.P. (Eds.), Lectures on the diencephalon, pp. 100-113. Elsevier. Publ. Co., Amsterdam, 1963.

Andersen, P., Eccles, J. C., Schmidt, R. F. And Yokota, T. Depolarization of presynaptic fibres in the cuneate nucleus. J. Neurophysiol., 27: 92-106, 1964.

Andersen, P., Eccles, J.C. And Sears, T.A. Cortically evoked depolarization of primary afferent fibres in the spinal cord. J. Neurophysiol., $27: 62-77,1964$.

Bishop, P. O., Jeremy, D. And Lance, J. W. The optic nerve. Properties of a central tract. J. Physiol., 121: 415-452, 1953.

Bishop, P. O., AND MAcleod, J.G. Nature of potentials associated with synaptic transmission in lateral geniculate of cat. J. Neurophysiol., 17:387-414, 1954.

Eccles, J.C., Eccles, R. M. And Magni, F. Central inhibitory action attributable to presynaptic depolarization produced by muscle afferent volleys. J. Physiol., 159: 147-166, 1961.

Eccles, J.C., Magni, F. And Willis, D. Depolarization of central terminals of Group I afferent fibres from muscle. J. Physiol., 160: 62-93, 1962.

Eccles, J.C., Schmidt, R.F. And Willis, W.D. Depolarization of central terminals of Group Ib afferent fibres of muscle. J. Neurophysiol., 26:1-27, 1963a.

Eccles, J.C., Schmidt, R.F. ANd Willis, W. D. Pharmacological studies on presynaptic inhibition. J. Physiol., 168: 500-530, 1963b.

Eccles, J. C., Schmidt, R. F. AND Willis, W. D. Depolarization of the central terminals of cuneate afferent fibres. J. Neurophysiol., $26: 646-661,1963 \mathrm{c}$.

Eccles, J. C., Schmidt, R.F. ANd Willis, W. D. Inhibition of discharges into the dorsal and ventral spinocerebellar tracts. J. Neurophysiol., 26: 635-645, 1963d.

Frank, K. And Fourtes, M. G.F. Presynaptic and postsynaptic inhibition of monosynaptic reflexes. Fed. Proc., $16: 39-40,1957$.

Schmidt, R.F. The pharmacology of presynaptic inhibition. Eccles J. C. And Schadé J. P. (Eds.), Physiology of spinal neurons, pp. 119-134, Elsevier Publ. Co., Amsterdam, 1964.

Schmidt, R.F. AND Willis, W.D. Intracellular recording from motoneurons of the cervical spinal cord of the cat. J. Neurophysiol., $26: 28-43,1963$ a.

Schmidt, R.F. AND Willis, W. D. Depolarization of central terminals of afferent fibres in the cervical spinal cord of the cat. J. Neurophysiol., 26:44-60, 1963b.

Vastola, E.F. Antidromic action potentials in lateral geniculate body. J. Neurophysiol., 20 : 167-185, 1957.

WALL, P.D. Excitability changes in afferent fibre terminations and their relation to slow potentials. J. Physiol., 142: 1-21, 1958.

WidÉn, L. AND AJMONE-MARSAn, C. Effects of corticopetal and corticofugal impulses upon single elements of the dorsolateral geniculate nucleus. Expt. Neurol., 2: 468$502,1960$. 